\title{
DESIGN THINKING MODELS IN DESIGN RESEARCH AND EDUCATION
}

\author{
Andra Irbīte \\ Aina Strode \\ Latvia
}

\begin{abstract}
Design thinking has become a paradigm that is considered to be useful in solving many problems in different areas: both in development of design projects and outside of traditional design practice. It raises the question - is design thinking understood as a universal methodology in all cases? How it is interpreted in design education? The analysis of theoretical and design related literature indicates different basic and contextual challenges facing design today: increasing scale of social, economic and industrial borders; complexity of environment and systems; requirements in all levels. As specialists and researchers in the field of design have concluded, here are multiple disconnects between what the graduate design schools are teaching at the level of methods and what skills is already needed. The problems have been found also in interdisciplinary cooperation and research.

In the context of design thinking models and problem solving methods, the analysis shows that design education implementers in public higher education institutions in Latvia are ready for local and global challenges.
\end{abstract}

Keywords: design thinking, design education, challenges, Latvia.

\section{Introduction}

Latvia is a relative newcomer to the design arena, still, the global labour market and the demands for the employed in the field of design are significant factors in the context of design education development .

The discussions between Ana Barroso and G. K. Van Patter (Van Patter, 2015a; 2015b) drew authors' attention. Theorists and practitioners, who study design or are engaged in one of its' fields, are usually divided into 'Design Community' and 'Non-design Community'. As G. K. Van Patter points out the problem is the „Failure/Slow Change on the part of deeply entrenched forces within the design community to allow Design Thinking to significantly evolve and change beyond their own traditional skillsets" (Van Patter, 2015a).

Are Design program graduates educated enough to find solutions in the face of different situations in their practice?

Although design education has become more interdisciplinary "it is mature the need for a new kind of designers, one that has traditional skills and yet a 
much broader perspective on problem identification and solving" (Quartz \& Co et al., 2011).

However, as pointed out by G. K. Van Patter (Van Patter, 2015b), "here is multiple disconnects between what the graduate design schools is teaching at the level of methods and what emerging practices is already working on, what skills is already needed. At that time and still today there was a heavy emphasis on product/service design in graduate design education".

The aim of the research: to summarize topical studies and opinions in design fields and in the context of education development, in order to set the aims of design education in Latvia, corresponding to the local and global challenges.

\section{Methodology}

The analysis of scientific and design related literature, the information available in the industry-related websites was carried out to ascertain the main challenges in the field of design and design education, as well as the essence of design thinking models and methodologies.

Triangulation method has been applied in the analysis of literature and information from design field related web sites and social networks.

In the study of design thinking models comparative analysis has been applied.

\section{The challenges in the field of design and education}

Today many companies worried by globalization are rethinking their production processes and questioning their beliefs in terms of business and marketing, and thus hiring massively and differently (Cumulus, 2015). In this context the authors of the article agree with the author of the book „Designer: Careers and Professionalization” (Guellerin, Minvielle, deJacquelot, 2010) summary (Cumulus, 2015): if in times past students were evaluated only based on their technical skills, in future even more will be need for designers who are willing to work with the more systemic and strategic approach in a larger scale.

K. Friedman (2003) points out that design as an integrative field in general is related to six common domains: natural sciences, humanities, social sciences, services, art, technologies and engineering sciences. „Design may involve any or all of these domains, in differing aspects and proportions. These depend on the nature of the project at hand or the problem to be solved" (Friedman, 2003). Depending on the problem to be resolved, activities and research in design process can be carried out on macro, average and micro level, and on each level it is necessary to use corresponding approaches and methods. 
Most frequently the reasons of failures are methods, as well as the lack of systemism and overall comprehension.

K. Friedman (2003) points to the basic and contextual challenges facing design today: increasing scale of social, economic and industrial borders; complexity of environment; requirements in all levels - production, distribution and control.

Basically the same idea in the context of design education is pointed out by G. K. Van Patter (2015b). „We (Humantific, aut.) identifying a dozen method related shifts underway in practice and not yet present in design education.

These include: (1) from tiny scale to large scale challenges; (2) from low complexity to high complexity; (3) from defined to fuzzy; (4) from internalized process to externalized process: (5) from downstream to upstream starting points; (6) from tactical to strategic; (7) from strangemaking to sensemaking \& changemaking; (8) from thinking \& doing to thinking, doing and enabling; (9) from prescriptive to orchestrative; (10) from intertribal communication to crossdisciplinary communication; (11) from deliberate exclusion to deliberate inclusion, from magic thinking to skill-to-scale, etc. (Van Patter, 2015b).

As the problem G. K. Van Patter (2015b) indicates the necessity to clarify the term 'Design Thinking' as an approach and united, universal methods as a set for the achievement of different goals.

In order to clarify how the process of design, referred to as 'Design Thinking', is interpreted, in the further research the authors analyse the information from scientific literature and web sites related to the field.

\section{Design Thinking}

Like the term 'design', the term 'design thinking' also does not have a single, generally accepted definition. Various authors offer explanations and interpretations of the term. Basically three discourses are distinguished in the literature on design thinking: design discourse, cognitive discourse and management discourse (Haasi \& Laakslo, 2011).

Design thinking is defined also as an innovation and a strategy oriented approach that "blends an end-user focus with multidisciplinary collaboration and iterative improvement to produce innovative products, systems, and services" (Meinial \& Leifer, 2011).

As new design fields are developing, the understanding of design thinking is associated with complexity and systems theories (Dunne \& Martin, 2006; Wieland \& Kaartemo, 2011; Pourdehnad et al., 2011). J. Pourdehnad (Pourdehnad et al, 2011) believes that first generation design thinkers are professional designers who develop design projects for clients using corresponding approaches and methods. Second generation design thinking is 
related to obtaining and aggregation of fragmented information from different interested parties, in order to develop design solution. Third generation or design thinking in the systemic thinking discourse: interested parties are designers, and the best way of ensuring the success is to allow each of them to formulate what design is. The success in this context is directly proportional to the level of interest. Forth generation design thinking is systemic.

After summarizing the information in the scientific literature, web sites and social networks, the authors come to the conclusion that the term 'Design Thinking' is interpreted according to the concept of design - both as the creation of material/non-material values, and strategic and systemic approach in the problem solving. It is impossible to create one design thinking model and methodology suited to achieve any goal in any context and scale.

The authors continue with the analysis of design thinking models in the context of different problem solving, proposing the following criteria:

a) the starting point for work/reference;

b) provisional results;

c) design process;

d) the scale of the problem;

e) methodics.

\section{Design thinking models}

Design thinking models indicate the research structure that is a logical consequent system of methodological, methodical and organizationally technical procedures that allow obtaining credible data on researchable phenomenon or precessing and applying it in practice for process management and predicting.

1. The process that starts with clearly defined goals/tasks and assumptions on anticipated results (linear process).

Linear design cycle: analysis $\rightarrow$ synthesis $\rightarrow$ development $\rightarrow$ judgement making, that continues with optimization, evaluation and implementation (Asimow, 1962), corresponds to recursive process logic by A. H. Bridges (1986). The goals and tasks in the linear design process are clearly defined, solution could be evaluated as correct or incorrect, the task of work (problem) belongs to the set of similar problems, all of which are solved in this way or another, limited alternative solutions are possible (Conklin, 2006). This design process is suitable for the development of small-scale projects, where terms and restrictions are known or quickly identifiable.

2. The process that starts with defined goals/tasks and partly predictable results (dynamic process). 
As admitted by M. Compton and S. Barrett (2015), the design process is often non-linear and complex, involving simultaneous consideration of multiple types of information", thus, design development is a dynamic process.

Design schools (Stanford University, 2016a; Singapore Polytechnic, 2016; Aaalto University, 2016), enterprises and organizations (IDEO, 2016; Design Council, 2008) offer design process/thinking models that are mostly divided into three (IDEO, 2016) four (Singapore Polytechnic, 2016; Aaalto University, 2016; Design Council, 2008) or five phases (Stanford University, 2016), also including feedback between stages.

A defined number of phases in practice do not exclude the division into smaller intermediate stages or merging of separate stages.

A range of methods is offered in design research and practice, in order to comprehend the basic problem, users' needs (qualitative research, observations, ethnographic studies, surveys, focus group interviews, data analysis and synthesis), to work in a team, to present a project, as well as creative thinking techniques.

This is an approach, that is based on analogies with designing process: the research of users needs/terms, interactive designing process and „learning by doing", suits for the development of new products/services and the perfection of existing ones on a wider scale, and undeniably for the learning process, as well as it could be part of the development of a complex project.

3. Partially or fully systemic process that starts with defined goals/tasks and partly predictable results. A similar starting point is in a 'Double Diamond' (Design Council, 2008) design thinking model (Figure 1).

This model, used in business and marketing, basically includes all the components and methods (qualitative and quantitative) of strategy development and suits for a work in a team.

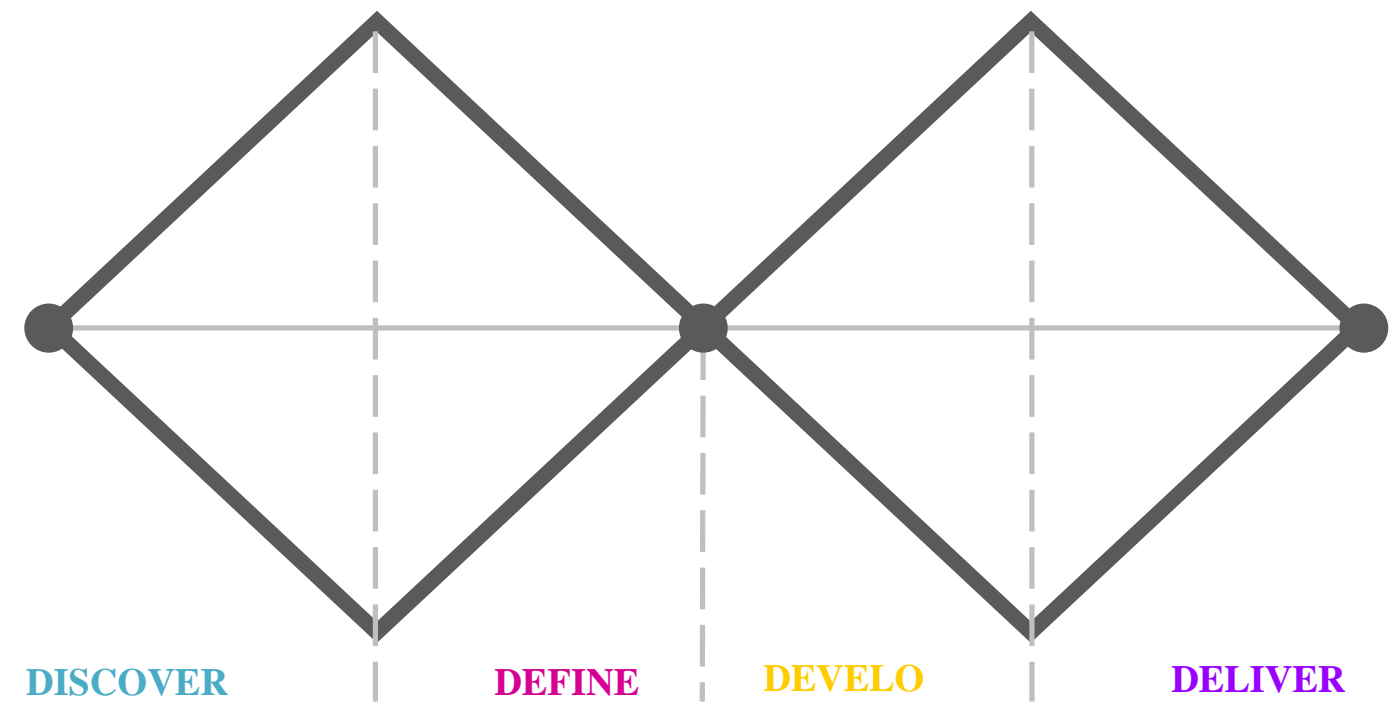

Figure 1 Design Thinking 'Double Diamond' Process Model (www. onemillionsigns.com) 
The model presents four main stages across two adjacent diamonds. As illustrated in the Double Diamond model's first diamond, the problematisation and understanding of a problem are equally important. Each of the four stages is characterised by either convergent or divergent thinking (Double diamond, n.d.).

4. A design process, that starts without assumptions on the possible results (dynamic, systemic, upgoing process).

This model is necessary in cases when basic problem is defined, changes are required, but it is not known how to achieve it.

This approach is related to complex problem solving, systemic approach and interdisciplinary research in the development of medium and large scale strategic, economic, politic, environmental and social projects.

Systemic thinking that stems from the systems theory is an approach and methodologies, in order to obtain thorough knowledge and create concepts on the essence of reality (Mattesich, 1982). Systemic thinking replaces reductionism (firm belief that anything could be divided into components and evaluated isolatedly), determinism (fatalism) with expansion (a system can always be a part of a bigger system) and indeterminism (probabilistic thinking) (Pourdehnad et al., 2011).

Politology and social sciences are related to so-called „soft systems": open, dynamic systems - life systems, social systems and their research methodologies.

The problems are caused by the root of the problems being solved - part of them are "wicked" (Rittel \& Weber, 1973). Unstructured, unclearly defined problems belongs to the group of social problems, characterized by the variety of information, a great number of involved parties and decision makers, contradictory values and hardly definable framework, because every problem is linked with another problem (Conklin, 2006). In the problem solving of such type a wide range of quantitative and qualitative methods can be applied.

As the problems to be solved are mostly multidimensional, the development of a project is divided into separate disciplinary components or modules. In the process of interdisciplinary design, while defining overall goals, tasks and values, the points of contact of modules and their functioning boundaries, objective parameters for evaluation of the overall solution, each of the parties involved develop a certain part of the project. The merging of project components, acknowledging that there are only a few possible solutions, occurs choosing one, that will satisfy the best all the parties involved (Conklin, 2006).

The communication in an open system could be considered as an integrated process. The identification of new contact points and information flow between the system elements is a crucial factor, and to a large extent the component functioning dynamics that as a catalyst can positively affect the development of hierarchically higher system modules depend on it. 
As systemic or Next Design Thinking, Humantific (Pastor, 2013) approach is interpreted, which includes both Design Thinking in design discourse, Applied Creativity Thinking, Systems Thinking, and also such modules as Open Innovation, Visual Sense Making, Innovation Acceleration, Design Research, Team Dynamics, Culture Construction, Organizational Change Making. The process begins with two questions - what might? and what might we? In fact, in this case the answer to the second question defines the scope and structure of the project as well.

The conclusions of the chapter. While analysing design thinking models and the essence of a problem to be resolved, the authors conclude that in the 1st and partly also in the 2nd case they are more analogous to 'Red Oceans' strategy logics - for the improvement of competitiveness within the framework of the value chain, although, they do not exclude the possibility of finding principally new solutions.

However, also in the case of the Double Diamond design process, the starting point - ,initial idea or inspiration in which user needs are identified", is not applicable in situations when existing problem is only an upper layer or easily identifiable part of interrelated problems.

In the 4th case the specifics of the project development states the necessity for the interdisciplinarity and a wide cooperation network.

In the process of design education this approach and methodologies, according to the possibilities and necessity, could be included both in interdisciplinary study programmes and programmes of traditional design fields.

Although there are different approaches and a range of applicable methods in design thinking models, the authors consider them impossible to be classified into progressive and outdated ones.

In this context, the authors agree with G. K. Van Patter (2015a) -, when design thinking is concerned, the most important thing is to comprehend the relations between the context and methodology. Design thinking must change according to challenge scale and in each case an appropriate set of methods should be used - upstream tools are different from downstream tools.

As an example, the experience of one of the most successful interdisciplinary design companies - IDEO (2016) could be mentioned. This company develops projects at micro and macro level: both traditional design projects, Business design, Organizational Design and also social innovation projects in order to design new strategies, programs, services, products and communications. The range of methods applied depends on the projects' specificity: qualitative, quantitative and strategic methods, as well as both analytical tools and generative techniques (IDEO, 2016).

IDEO's CEO, T. Brown (2016) marks out several relevant fields that nowadays are most in need for design: 
1. Serving the needs of the global poor.

2. Designing new approaches to health, including aging and the end of life.

3. Designing healthy and profitable food systems that can serve the needs of all.

4. Designing citizen-centered government services.

5. Designing the future of our urban communities.

6. Anticipating the opportunities and challenges of over-the-horizon technologies.

7. Designing the future of work and the corporation itself.

It also determines the scale of cooperation and creates preconditions that promote the merging of separate design companies into creative unions, like kuy (Kuy, 2016).

In order to work at such scale, T. Brown (2016) points out the design problem nowadays: the necessity for new rules of engagement with a broad set of collaborators.

\section{Discussion}

The change of the scale, the accent and the nature of work in design practice states the necessity for improvement in design education as well.

At this point it is necessary to return again to the interdisciplinary cooperation and research that in design literature does not lose its topicality.

As concluded P. Le Masson, K. Dorst and E. Subrahamanian (2013), even more than in the past, the renewal of design theory should lead to a body of sustainable, collective research. „In the broadest sense, the renewal of design theory should help to understand and support contemporary forms of collective action. Recent advances open the possibility to invent new methods, new organizations, and new forms of collaborations inside and between organizations. And - these theories could provide the basic corpus and language to educate the designers of tomorrow in the logic of creation" (Le Masson et al., 2013).

However, analysing the opinions of the employed in the field of design, problems that design education must solve in the nearest future are clearly outlining.

L. Grocott and M. Kobori (2015) highlights experiences in collaborating with scientists from other fields which led them to see the paradigmatic difference between a scientific line of inquiry and a performative approach to exploration as the primary. Considering the contribution of design expertise in the learning sciences researchers (Grocott \& Kobori, 2015) identified the discovery-led orientation of design as a strength and the lack of experience with 
metrics for evaluating research as a deficit. These conclusions point to the necessity to apply methods that will allow proving the credibility of design solutions.

K. Friedman (2003) believes that one of the deep problems in design research is the failure to develop grounded theory out of practice - designers often confuse practice with research. Yet the authors doubt that the summarization of separate persons' experience, that is clearly necessary, could disclose something more that it is already known and resulted in Design Thinking comprehension in the design discourse.

M. Compton and S. Barrett (2015) predict that in addition to challenges in industry, there are obviously going to be some challenges in education: (1) the relevance of research to the self-identity of the artist and designer; (2) a lack of institutional support for including research in art and design curriculum; (3) the question of whether art and design education community needs it's own Institutional Review Board (IRB).

K. Friedman (2011) concludes that researchers face challenges in interdisciplinary research arising from social, cultural, and conceptual barriers.

Designers could hardly be blamed for these problems.

An essential role plays the experience acquired in the process of professional education, where it is expected to improve design education, providing students with more profound knowledge, the development of research skills and abilities in design and related inter-fields, as well as to train for independent scientific research activity, that enables the capability to plan, implement and evaluate, orient towards lifelong learning and professional development.

\section{Experience and challenges in the development of design education in Latvia}

In the same way as in other countries, the structure of design education in Latvia corresponds with the demand for labour force in the economic sectors. Design education is a part of professional education in Latvia, therefore, the curricula are based on the requirements of professional standards set for the employed in the design fields.

In public universities, that are also scientific and research institutions, design programmes have been developed relatively recently. The main benefit for design educators and students are the opportunities to cooperate with students, pedagogues and scientists of other fields.

Research activity is integrated into the curriculum and the study process. The paradigm of design thinking is viewed critically, emphasizing more the way of thinking, obtaining information and the aspects of analysis, as 
well as the competencies obtained during the project development. Comparing design thinking models, in design education in Latvia, regardless of the design field and terms of reference, there is a systemic approach to the work process, also integrating the process and methodology based on recursive logic.

The interdisciplinarity is highlighted as one of the most essential basic elements of higher education in design. The emphasis has been placed on design research and methodology in the social and business environment. The international, interdisciplinary development of study programmes and research competences is relevant. It complies fully with the implementation of „Project Europe 2030" (2010) tasks, that emphasizes various skills of the inhabitants, including skills in the digital field, ability to study, the development of cultural comprehension and the encouragement of the initiative and an entrepreneurial spirit, as well as provision of functioning knowledge triangle: educationresearch-innovation. The partnership between business environments, national and regional authorities and field educational and research institutions, as well as international cooperation of higher education institutions and experience of design companies of other countries could help to define competences and skills that are necessary in labour market.

As the experience of other countries has shown, the formation of shared comprehension of the role of design and cooperation among designers, representatives of the national and regional authorities, organizations and entrepreneurs brings positive results in the development and functionality of products and services, producing and marketing.

This is the main challenge in design education in Latvia, that defines both the need for the development of new interdisciplinary study programmes, and the necessity to perfect the theoretical and methodological base of the design field, as well as to continue to extend the cooperation and communication networks.

\section{Conclusions}

- Today the design industry is facing various basic and contextual challenges: increasing scale of social, economic and industrial borders; complexity of the environment; requirements at all levels.

- If in times past students were evaluated only based on their technical skills, in future even more will be need for designers who are willing to work with the more systemic and strategic approach in a larger scale.

- Most frequently the reasons for the failures of design projects and cooperation are methodics, as well as the lack of systemism and comprehensive understanding. 
- The term 'Design Thinking' is being interpreted according to the concept of design - both as a process of material/non-material value creation, and as a strategic and systemic approach to problem solving.

- The design thinking models based on the recursive logic and their methodics are not suitable for solving complicated systemic problems, but they could be the project development components.

- Design Thinking must change according to challenge scale and in each case an appropriate set of methods should be used.

- Interdisciplinary cooperation and research as an ensurance of the design development process should be the base of the design education. For this purpose, it is necessary to increase the theoretical and methodological base in the field of design.

- The main challenge of design education in Latvia is the need to continue to develop and strengthen interdisciplinary and interinstitutional cooperation and research.

\section{References}

Aaalto University. (2016). Executive programs. Design Thinking for Business. Retrieved 21 January, 2016, from http://www.aaltoee.com/program/design-thinking-businessinnovation/general-info.

Asimow, M. (1962). Introduction to Design. Englewood Cliffs, Prentice-Hall. Retrieved 12 January, 2016, from http://catalog.hathitrust.org/Record/001512094.

Bridges, A. H. (1986). Any progress in systematic design? CAAD Futures digital proceedings (pp.8-9). Retrieved 21 December, 2015, from http://cumincad.scix.net/data/ works/att/a6f1.content.pdf.

Brown, T. (2016). The Next Big Thing in Design. Retrieved 21 January, 2016, from https://medium.com/ideo-stories/the-next-big-thing-in-design-513522543a6f\#.h2lu74oan..

Compton, M., \& Barrett, S. (2015). Grounded Theory in Art and Design. Proceedings in International Conference for Design Education Researchers, Volume 3, pp.1164.

Conklin, J. (2006). Dialogue Mapping: Building Shared Understanding of Wicked. Retrieved 12 January, 2016, from

http://www.ideapartnership.org/documents/wickedproblems.pdf.

Design Council (n.d.). A study of the design process. Retrieved 12 January, 2016, from http://www.designcouncil.org.uk/sites/default/files/asset/document/ElevenLessons_Desi gn_Council\%20(2).pdf

Double diamond. (n.d.). Retrieved 21 January, 2016, from https://innovationenglish.blogs. $\mathrm{ku} . \mathrm{dk} / \mathrm{model} /$ double-diamond-2/.

Dunne, D. \& Martin, R. (2006). Design thinking and how it will change management education: an interview and discussion. Academy of Management Learning \& Education, 5(4), 512-523.

Cumulus (2015). First Cumulus Think Tank - Designer: Careers and Professionalization. Retrieved 25 November, 2015, from http://www.cumulus association.org/academics/page/2/. 
Friedman, K. (2003). Theory construction in design research: criteria: approaches, and methods. Design Studies, 24(6), 500-519. Retrieved 13 January, 2016, from https://www.academia.edu/2508830/Friedman._2003._Theory_Construction_in_Design _Research_Criteria_Approaches_and_Methods.

Friedman, K. (2011). Interdisciplinary Research: The Challenge. Retrieved 10 December, 2015, from https://www.academia.edu/3727725/Friedman._2013._The_Challenge_ of_Interdisciplinary_Research.

Grocott, L., \& Kobori, M. (2015). The Affordances of Designing for the Learning Sciences. Proceedinggs in International Conference for Design Education Researchers (Volume 3) (pp.1181-1182). Retrieved 10 January, 2016, from https://www.academia.edu/13300472/International_Conference_for_Design_Educa tion_Researchers_volume_3 .

Guellerin, C., Minvielle, N., De Jacquelot, M. (2010). Designer: Careers and Professionalization. De Boeck. ISBN: 978-2-8041-6015-9.

Hassi, L., \& Laakso, M. (2011). Design Thinking in the Management discourse; defining the elements of the concept. Retrieved 24 November, 2015, from http://www.mindspace.fi/ wpcontent/uploads/2013/12/HassiLaakso_2011_IPDMC.pdf .

IDEO (2016). Expertise. Retrieved 12 January, 2016, from https://www.ideo.com/about/.

Kuy (2016). Retrieved 21 January, 2016, from http://kyu.com/\#overview .

Le Masson P., Dorst, K., Subrahamanian, E. (2013). Special Issue on Design Theory: history, state of the arts and advancements. Research in Engineering Design, 24(2), 223-243.

Retrieved 12 January, 2016, from https://hal.archives-ouvertes.fr/hal-00870323/ document.

Mattessich, R. (1982). The systems approach: Its variety of aspects. Journal of the American Society for Information Science, 33(6), 383-394.

Menial, C., \& Leifer, L. (2011). Design Thinking Understand - Improve - Apply. Heidelberg

Norman (2014). Why Design Education Must Change. Retrieved 10 January, 2016, from http://www.jnd.org/dn.mss/why_design_education.html.

One million signs (n.d.). Double Diamond. Retrieved 12 January, 2016, from http://www. onemillionsigns.com

Pastor, E. (2013). The OTHER Design Thinking. Retrieved 12 January, 2016, from http://www.humantific.com/the-other-design-thinking/

Pourdehnad, J., Wexler, E.R., Wilson, D.V. (2011). Systems and Design Thinking: A Conceptual Framework for Their Integration. Retrieved 21 January, 2016, from http://repository.upenn.edu/cgi/viewcontent.cgi?article=1009\&context=od_working_pa pers.

Quartz \& Co, the Danish Enterprise and Construction Authority; the Danish Ministry of Culture (2011). Mapping of International Design Policies and Strategies for leading design schools and research institutions, pp.23. Retrieved 17 February, 2015, from http://erhvervsstyrelsen.dk/file/163743/mapping_international_design_policies_strategi es .pdf.

Project Europe 2030. Challenges and Opporunities. (2010). Luxembourg: Publications Office of the European Union. Retrieved 15 December, 2015, from https://www.consilium.europa.eu/uedocs/cms_data/librairie/PDF/QC3210249ENC.pdf

Rittel, H., \& Webber, M. (1973). Dilemmas in a general theory of planning. Policy Sciences, 4(2), 155-169.

Singapore Polytechnic (2016). SP's Design Thinking Framework. Retrieved 21 January, 2016, from http://ejuz.lv/7f3. 
Proceedings of the International Scientific Conference. Volume IV, May $27^{\text {th }}-28^{\text {th }}$, 2016. 488-500

Stanford University, Design Institute (2016). The Design Thinking Process. Retrieved 21 January, 2016, from http://dschool.stanford.edu/our-point-of-view/\#design-thinking.

Van Patter, G. V. (2015a). Making sense of: „, Why Design Thinking Will Fail”. Retrieved 15 December, 2015, from https://www.linkedin.com/pulse/making-sense-why-designthinking-fail-gk-vanpatter.

Van Patter, G.K., \& Friedman, K. (2003). New Design Research: Leading or Following? Next D Journal, 2, 9.

https://www.academia.edu/3728316/NextD_Journal_2_New_Design_Research_Leading_or_ Following_GK_VanPatter_and_Ken_Friedman.

Van Patter, G. K. (2015b). Talking about Sensemaking, Part 2, Origins of NextDesign Geographies. Retrieved 15 December, 2015, from https://www.linkedin.com/ pulse/origins-nextdesign-geographies-gk-vanpatter?forceNoSplash=true

Wieland, H., Kaartemo, V. (2011). Complexity by Design. Retrieved 15 December, 2015, from http://www.naplesforumonservice.it/uploads//files/Wieland,\%20Kaartemo\%20 Complexity\%20by\%20Design.pdf 